\title{
The Application of Computer Music Technology to College Students
}

\author{
Na Wang \\ College of Music, Beihua University, Jilin City, China
}

\begin{abstract}
Contemporary music education started late in China on the basis of western teaching theories formed its own unique system, which has a great influence on present computer music technology. This paper explores that contemporary music education is analyzed advantages and disadvantages of the influence on the development of Chinese class music, and the solutions are found out to the existing problems, summed up the reality enlightenment of that the contemporary music on the impact of education.
\end{abstract}

\section{General instruction}

Mid-20th century to the early 21 st century, with the computer music technology swept through Europe and Japan and other developed countries, the development of computer technology, more and more with each passing day the music. Today, every music lover can take advantage of a complete computer music platform for music learning and creation. Musicians can be computer via MIDI (Musical Instrument Digital Interface) interface to connect electronic musical instruments constituting the system, so as to receive, control and adjust the level of sound, such as, length, timbre, dynamics, etc., through the different sources of reality "sampling" and then use the ever-changing variety of methods for processing sound, creating one can not imagine the sound. With MIDI standards, the traditional acoustic music science, law school system, acoustics, musical school, orchestration school has also undergone unprecedented revolutionary change. At the same time, by MIDI technology and multimedia technology and network information technology development and maturity, MIDI equipment, computers and music software has become increasingly closely integrated, which makes traditional music, music and dramatic changes occurred in music teaching, but also it makes people's awareness of computer music technology gradually deepened.

Now, with a highly developed computer music technology, the effects and benefits of computer generated music technology is constantly broaden people's understanding of music, these effects and benefits of music education, teaching film, radio, television, music recording, music, etc. areas to be widely used, and has played an important role. And computer music technology has infiltrated more and more areas of music education, teaching conception. With music and computer technologies have become increasingly closer in the field to produce a large number of excellent music.
Overall, now commonly used in computer music technology software: Encore, Final. Popular sequencer software: Cakewalk, Cubase. Common harmonies teaching software: Version50 and Musicator win30 and so on.

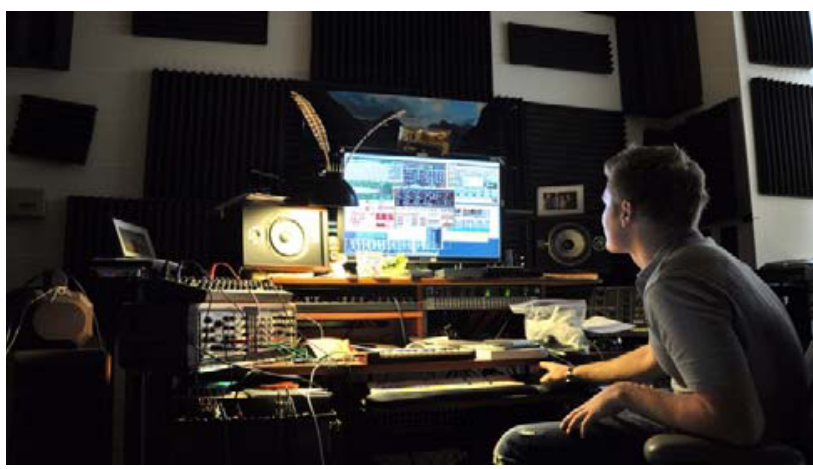

Figure 1. Computer music technology system

\section{Computer music technologies}

In China, computer music key technical points are purely artistic or purely commercial musical studies on production. In the computer music technology into the classroom music education, especially of the Normal University music theory class professional in this field, in general, it is not very common. Although the Ministry of Education in August 2001 issued the "Opinions on strengthening undergraduate teaching work to improve the quality of teaching," the document presented twelve strengthening undergraduate teaching work measures to improve the quality of teaching and the views and The Ministry of Education "2003-2007 Action Plan for Invigorating Education" an important part of the "Quality Project" in the proposed "information technology as a means to deepen education reform and personnel training mode reform," but confined to China's national conditions, almost close the file to "empty talk." This is 
because :( a) In China, people use computer music technology research started relatively late, the computer MIDI and multimedia systems in college music teaching is still in the development stage. (B) As Chinese music system from the west, and gradually formed in the Chinese Modern specific political, economic, cultural and educational background, it is difficult to make up for its shortcomings. (C) At present normal student's computer music technology education relatively low starting point, teacher-student ratio is too large, plus an abstract theory courses, sound unstable, these factors greatly enhance the difficulty of computer music technology teaching.

Due to computer music technology teaching has its particularity, so the shortage of teachers, teaching facilities, inadequate case basis, only to study and explore the "plots" in the form, and on this basis to explore and build suitable for China Music Education. Currently, computer music technology application in China Teachers Teaching is not widespread; the reason is mainly reflected in the following three aspects:

First, in China, due to computer applications, penetration is not high, resulting in computer music technology started relatively late in Europe and other developed countries. Therefore, only a small part of the music research institutions, universities and teachers have the ability to use a computer music technology teaching;

Second, in our country, due to the traditional mode of thinking educational atmosphere, thus familiar with computers and courseware production of computer music teacher is not much;

Third, the current in Normal Colleges in China, there is no package, the use of computer music technology hardware facilities for teaching music; To sum up, the computer music technology in Normal computer music technology teaching in our country, but also in a "bottleneck" status. Teacher alone a mouth, a stereo equipment, it is difficult to approach a new orchestration, timbre colourful works thorough explanation to students, and the students also difficult to make a rational analysis of computer music technology to produce sound effects, and to be fully understanding. Therefore, only effective by music from the "visual arts" to "auditory art", a breakthrough in theory, various limitations on teaching methods, in order to ease the contradiction between "teaching" and "learning" to fundamentally improve teaching quality, make computer music technology to achieve a qualitative leap in teaching fundamental in order to better discover and cultivate excellent comprehensive quality talent.

\section{The importance of computer music technology into the teaching of music in Normal}

Ancient educator Confucius lifetime love of music and cool love to sing, and music as one of the six arts student compulsory proposed "Xing in poetry, stand ceremony, as with the music.
With the advent of the knowledge economy, a necessary requirement with suitable educational system, from the examination-oriented education steering train all-round development of innovative talents as the goal of quality education. We know that cultivate people's all-round development and innovation capacity must be built on all the psychological, physiological basis for the development of people's abilities above, such as human feeling, perception, understanding, insight, transform, divergent thinking and so on. And there will be conducive to art cultivating the basic quality of the human form. American University of Iowa Phillips (K Phillips) in the United States, "Music Educators Journal" published an article entitled "Music education is the basic idea of the establishment of a more powerful," the article, presents music important for human development resistance, which we fully understand the important position of music in education is very useful.

History of our country and the rest of the world of educational technology development tells us that any successful application of an advanced technology in education, first of all depend on the concepts of education educators update. Similarly, computer music technology into Music Education, but also by the trend of historical development decisions, and its importance can be summarized as four points:

First, the computer music technology education has a very important role in the successful implementation of quality education in. This is because: computer music technology education is a basic form of the new era of human and cultural exchanges, such as language and literacy, as it is, between human beings communicate thoughts, ideas and feelings, but also we learn a world cultural heritage of all ethnic groups important means it helps us understand the character and individuality of human culture, help us to know themselves, know our traditions and thinking behaviour. At the same time, through the computer music technology, we can get to know other peoples and their traditions and behaviour. Understanding of human cognition, psychological, emotional, and kinaesthetic On a deeper level, in order to develop and improve the knowledge of human beings, profoundly change people's attitudes and emotions. And learn computer music technology can develop and exercise the human imagination and thinking skills, in order to develop the broadest perspective, from the perspective of the natural sciences, social sciences and other infrastructure areas, sublimation human soul, to truth, goodness and beauty of harmony and unity.

Second, the computer music technology education in the New Chinese music education system reform in the key. This is because: China Music Education Curriculum System in the early 20th century, imported from the West, is in the Chinese Modern specific background of politics, economy, culture, art and education evolving. Today, the music education curriculum system has increasingly shown its drawbacks and defects, specific performance: 1, music relatively narrow field of vision. That is now China's music education system rarely reference value of 
ancient Chinese music and traditional music, just blindly absorb Western music mode and content, while ignoring the big nations of the world music culture system development. 2, Music education is the form of relatively simple. That most school music education is closed single musical education rarely comes to integrated interdisciplinary teaching. 3, Music backward is failure to music education into major development trend of the times among the global technology. In application of computer music technology, for example, currently many domestic professional music creators use, and school education rarely use.

Third, the importance of education in computer music technology is to build a new music education mode. Innovative educational technology, especially in contemporary music technology and multimedia computer network of general application, the traditional teaching methods and teaching philosophy has changed dramatically, the use of new technologies in teaching makes teaching more obvious, more conducive to cultivating wealthy individuality and innovative students to help improve overall quality of students.

Fourth, computer music technology into music education is to help speed up the training of teachers. Comrade Jiang Zemin as early as the end of 1997 the national organization of the session, had said: "Today is a time of new things, new knowledge, new experiences emerging era, many of us want to learn something, no matter who, as long as the halt, do not learn something new, is certainly to be outdated. "So, in the face of a new era of rapid development of computer music technology, every teacher need to keep learning and training, it is necessary to do: 1, learning computer music technology, including hardware use of knowledge and common knowledge to use music software. 2, learning modern music education theory, establish the concept of quality education, educational research, computer music technology creatively applied to the school teaching, and to achieve the goal of interdisciplinary music education.

In the face of the future of education, the key is to learn the students to learn, learn to use, learn and create. Obviously, with the introduction of computer music technology classes, which will maximize the current situation improved and enhanced, and to achieve convergence and integration with the world trend of curriculum reform and international music education.

\section{Computer music technologies in harmony Course}

Harmony class conservatories and music faculties Normal Universities in the more important a subject, it is the basis for polyphonic, orchestration, musical and other technology Theory. Features harmony lesson is that it is a highly theoretical course, but also needs a lot of practice of course, there is not enough understanding of the practical exercises, and even if reluctantly harmony theory is difficult to apply in practice.
In Normal College music faculty, the general traditional teaching methods are still blackboard plus piano, which also has been become the primary means of acoustic and teaching, due to China's general music education foundation is weak, many high school teacher and student before do not understand what is harmony, therefore, faced with this kind of teaching situation, the teachers "teaching" and "learning", to a certain extent, it is difficult to reach a tacit understanding. While students learn very seriously, but for harmony of knowledge and awareness is still a blur. Because of this traditional mode of teaching is difficult to form in the minds of students on the harmony sound auditory association, making their ears feel harmonic sound beautiful, so in terms of ideology can not form the most general harmonic thinking habits, learn In the end, most people have lost interest in learning to harmony. In a sense, this is the key to Normal and acoustic difficult to improve teaching quality lies.

How can we effectively address the theory and practice of teaching harmony out of touch, hearing student image and visual image difficult to communicate the problem? This requires us to introduce MIDI computer technology and multimedia systems in teaching. The general mainly US Passport Designs has developed "Encore" notation software (vision4.2.1), UK Software Partners Company "Tonica" Harmony teaching software (Vision 5.0) and the United States jointly with the Norwegian Jo Brodtkord MusicatorA / S Company development "Musicator Win 3.0 (MW30)" music software, and utilization of their special features, depending on the students, listening to the integration of multimedia teaching harmony, the main approach is as follows:

(A) The use of Encore score display functions lectures.

Encore has a very intuitive score display function, use this feature, you can teach in harmony with the actual sound spectrum of cases in the classroom teaching harmony synchronized show in front of students, and can be quickly re-presentation. For example, the harmony of a specific connection, teachers can teach the basic laws while writing, through computer technology to play MIDI out its various manifestations, including different melodies position, a different arrangement position, a different sound range changes in areas such as acoustic factors. Students hear acoustic sound but also saw them score display, and according to their own auditory and visual perception, to teachers in the form of bomb various connections to make their own sound aesthetic judgment. Practice has proved that, in this manner harmony teaching lectures, students read, see, hear with, easy to stimulate students' interest in learning and aesthetic judgment of confidence.

(B) The use of MW3 score editing functions commented demonstration and job assignments.

MW3 score editing features are very good. When students analyze written assignments as well as assignments commenting demonstration in the classroom, using this feature can often achieve good results of 
replication. For example, the parallel connection and the most commonly occurring spin, reverse and concealed fifty-eight degrees and other bad parts were, you can use the Score Editor of copies (COPY) function, will include the above error chords connected to the bottom off the copy phase Pro track the location of the same beats, and using editing functions on the new track will delete unnecessary parts, leaving only two parts of the constitution in parallel, depending on the students, the problem will hear a glance, without further too much explanation. In making demonstration, the teacher can make a variety of different configuration with a harmony exercises. Then, MW3 monorail playback function, the various acoustic configuration obtained through classroom discussion so that students listen to each playback, audio-visual integration, in order to develop students' hearing ability and harmony thinking ability, and develop their aesthetic taste and elegant harmony.

(C) The use of different types of harmony Tonica learning style and help with harmonies change problem.

Tonica is a harmony of four devoted to the study of multimedia educational software. Compared with other software, although Tonica interface design is not friendly, but for harmony teaching it, Tonica proprietary exercise function can still play its positive role. For example: teachers in the classroom can be done for the melody (or bass) with examples of harmony or students after school made a written exercises, use Automatic Harmonize Tonica choose a different style to do another harmony several different harmony configurations, enable students to appreciate the technical differences between the different harmony styles. In addition, students can practice harmonies Tonica import MIDI file format, and use it for the correct operation of harmony. In the current harmony teaching classes many colleges take Taipan special circumstances, the use of Tonica help with harmonies change problem is undoubtedly a more viable harmony teaching methods.

(D) The use of real-time recording function performed MW3 Encore and keyboard harmonies play guidance.

Keyboard Harmony Teachers play an important part harmony teaching. In the past, teaching, students are required to do seeing chords mark, thinking connectivity rules, playing four hands harmony, but for various reasons, students are often at a loss when you play, playing the wrong tone while he did not know. MW3 Encore and use real-time recording function, students play before the record button is pressed, the recording will be played and synchronization is complete, and instantly generate a score, so fleeting keyboard harmonies play converted into concrete existence sheet music form. Student scores generated instant play site based on its guidance, help students find their own advantages and problems. In addition, to strengthen the cohesion harmony exercises and improvisational accompaniment keyboard curriculum, teachers can play the four students evolved into a common harmony accompaniment texture (or simple accompaniment figure) in new tracks by four - part Harmony outline contrasts with the accompaniment of texture, easier to stimulate students' interest in learning.

(E) Site

Classical MIDI Connection, http:// www. midiworld. com/cmc/index.htm. This site records the West from the Baroque period to the twentieth century composer's midi main resource. Covering a wide range, MIDI files are also musicians playing pro, high artistic taste, and sound analysis is used as the repository, the site is preferred.

\section{References}

1. Lee to Beijing. On the computer music teaching. Fujian Art, 21 (2001)

2. Chen Xiangming teachers how to do qualitative research. Education Science Press, 12 (2001)

3. Fang Zhining. Enchanting Midi Mongolia Press, 11 (2003)

4. Yong division. Computer music production master. Beijing Hope Electronic Press, 05 (2000)

5. Zhang Kai Educational Psychology, Southwest Normal University Press, 21 (2000)

6. Qin Qingkun .MIDI technology in music technology theory and practice of teaching. Hebei University Institute of Adult Education College, 14 (2000)

7. Research Lijian Qin Information teaching music teaching environment. Alto network, 13 (2004)

8. Han Biao. Mention mediated teaching methods using digital music Modern Music Education Personnel Training Network alto, 02 (2004)

9. Like Dong heart of modern music technologyConstruction of new forms of teaching mode China Education Daily, 07 (2010).

10. Li Jiahou. Computer music technology and audiovisual education innovation research and education, 18 (2009) 